(1)

\title{
Divergent paths to martyrdom and significance among suicide attackers
}

\section{David Webber, Kristen Klein, Arie Kruglanski, Ambra Brizi \& Ariel Merari}

To cite this article: David Webber, Kristen Klein, Arie Kruglanski, Ambra Brizi \& Ariel Merari (2015): Divergent paths to martyrdom and significance among suicide attackers, Terrorism and Political Violence, DOI: 10.1080/09546553.2015.1075979

To link to this article: http://dx.doi.org/10.1080/09546553.2015.1075979

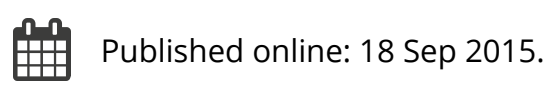

Submit your article to this journal ๔

Џlll Article views: 4

Q View related articles ¿

View Crossmark data ¿ 


\title{
Divergent paths to martyrdom and significance among suicide attackers
}

\author{
David Webber ${ }^{\mathrm{a}}$, Kristen Klein ${ }^{\mathrm{b}}$, Arie Kruglanski ${ }^{\mathrm{a}}$, Ambra Brizi ${ }^{\mathrm{c}}$ and Ariel Merari ${ }^{\mathrm{d}}$

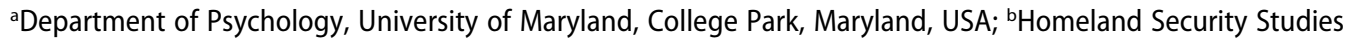 \\ and Analysis Institute (HSSAI), Analytic Services, Inc., Arlington, Virginia, USA; 'Department of Social and \\ Developmental Psychology, Sapienza University of Rome, Rome, Italy; dDepartment of Psychology, Tel Aviv \\ University, Tel Aviv, Israel
}

\begin{abstract}
This research used open source information to investigate the motivational backgrounds of 219 suicide attackers from various regions of the world. We inquired as to whether the attackers exhibited evidence for significance quest as a motive for their actions, and whether the eradication of significance loss and/or the aspiration for significance gain systematically differed according to attackers' demographics. It was found that the specific nature of the significance quest motive varied in accordance with attackers' gender, age, and education. Whereas Arab-Palestinians, males, younger attackers, and more educated attackers seem to have been motivated primarily by the possibility of significance gain, women, older attackers, those with little education, and those hailing from other regions seem to have been motivated primarily by the eradication of significance loss. Analyses also suggested that the stronger an attacker's significance quest motive, the greater the effectiveness of their attack, as measured by the number of casualties. Methodological limitations of the present study were discussed, and the possible directions for further research were indicated.
\end{abstract}

\section{KEYWORDS}

Martyrdom; motivation;

radicalization; suicide

The phenomenon of suicide and the motivations behind suicide have been of considerable interest to social scientists, ${ }^{1}$ as suicide contradicts life's most prepotent instinct to survive and escape death. ${ }^{2}$ On the surface, then, it seems perplexing that suicide bombing is the weapon of choice for terrorist organizations. ${ }^{3}$ From the organizational perspective, however, suicide bombers are an inexpensive yet highly effective weapon, ${ }^{4}$ accounting for only $4 \%$ of all terrorist attacks, yet fully $32 \%$ of terrorism-related deaths. ${ }^{5}$ Beyond sheer effectiveness, various propositions have been made regarding the organizational motivation behind suicide attacks, including a) removal of foreign occupational forces from one's homeland, ${ }^{6}$ b) collapsing emerging democratic structures and sparking violence between non-state actors, ${ }^{7}$ and signaling either c) the organizations' determination to use violence, ${ }^{8}$ or d) intense commitment to the cause in an effort to "outbid" other insurgent groups. ${ }^{9}$ Thus, in situations of asymmetric conflict, suicide attacks may function to level the playing field, and provide the best advantage to the weaker party in an imbalanced situation. 
Questions remain, however, regarding how organizations convince individuals to sacrifice their lives in suicide attacks and (relatedly) why individuals allow themselves to be so convinced. Whereas suicide might make sense for individuals who feel they have nothing to live for (e.g., those who perceive themselves as burdensome, perhaps due to depression, illness, or incapacitation ${ }^{10}$ ), researchers have pointed out that suicide bombers are relatively "normal" and neither suicidal nor particularly depressed. ${ }^{11}$

Although systematic empirical examinations of extremists' motivations are sparse, it is generally recognized that understanding the radicalization process requires moving beyond the organizational objectives, and examining the interplay of motives at various levels of analysis. For instance, Pape, who views organizations that launch suicide attacks as reacting primarily to foreign occupation, ${ }^{12}$ also sees suicide terrorism as grounded in mass support at the social level, and an instance of altruistic suicide ${ }^{13}$ (i.e., self sacrifice on behalf of others) at the individual level. Hafez likewise identified the individual motivational, organizational, and societal levels ${ }^{14}$ involved in suicidal terrorism, and more recently, Kruglanski and colleagues emphasized the interplay between individual-motivational, social, and cultural/ideological processes in terrorism more generally. ${ }^{15}$

\section{The quest for personal significance as the motivation for suicide attacks}

The latter authors' significance quest theory ${ }^{16}$ (SQT) suggests that at the individual level there might exist a common core in the panoply of previously identified reasons for attackers' sacrifice. These reasons have included honor, dedication to the leader, social status, glamour, personal loss, group pressure, humiliation, vengeance, restoration of Islam to its glory, monetary benefits, desire to enter heaven, and even feminism. ${ }^{17}$ Ricolfi referred to such a conglomeration of reasons as "a cocktail of feelings ... desire for revenge, resentment, and a sense of obligation toward the victims." 18

Though all the above reasons are likely to constitute valid descriptions of specific cases, their common motivational core according to SQT, however, is the quest for personal significance-the desire to count, to be someone, to be recognized, to matter in the eyes of one's group, according to its (sacred) values. ${ }^{19}$ Consider how the quest for personal significance may apply to the previously listed motives for suicidal terrorism. One could want revenge against those who have caused harm to them, their family members, or their group. The previously bestowed harm renders one powerless, reduces one's sense of value or esteem, and lowers one's sense of mattering and significance. Vengeance enables one to reciprocate the humiliation, thus providing an opportunity to restore one's lost significance, and hence level the playing field. Group pressure (akin to Pape's notion of "mass support") suggests that, in the eyes of others, one's significance would rise upon acceptance of the mission and decline upon its refusal. Dedication to the leader signifies that one's suicide would be respected by an admired figure, conferring considerable significance upon oneself. ${ }^{20}$ Social status and glory directly represent the attainment of significance, monetary support for family ensures their gratitude and adoration, and entrance to heaven symbolizes recognition afforded to particularly deserving, and hence, significant, individuals. As can be seen then, the concept of significance quest serves to integrate under a common umbrella a variety of seemingly disparate motivations mentioned in connection with suicide attacks. 


\section{Arousal of significance quest}

\section{Significance loss}

As with any motivational force, ${ }^{21}$ the need for personal significance must be activated to influence behavior. SQT identifies three intertwined conditions for such arousal. ${ }^{22}$ The first is significance loss, that is, humiliation or dishonor of some kind. Instances of humiliation reduce one's significance below normal levels, and motivate behavior aimed at restoring or augmenting it. Significance loss might result from an affront to one's social identity (e.g., religious, ethnic, or national). In this vein, terrorist propagandists (e.g., $\mathrm{Al}$ Qaeda's Anwar al Awlaki, or Yehia al Libi) often allude to injustice experienced by Muslims in remote world locations (e.g., Bosnia, Afghanistan, Iraq, or Syria) to imply that Muslims everywhere share their humiliation. Significance loss can also arise from a person's unique humiliation that may be unrelated to category membership, for instance, personal failure or transgression against an important social norm. This can be seen in Palestinian suicide attackers who volunteered after suffering stigma in their community as a result of personal circumstances (e.g., infertility, divorce, extramarital affair, HIV diagnosis). ${ }^{23}$ These personal circumstances had little to do with the attackers' Palestinian identity or with the Palestinian-Israeli conflict, yet they were perceived as losses of self-worth that could be redeemed by sacrifice on behalf of one's group.

Note that the concept of significance loss is similar in some sense to relative deprivation, which has been used to explain why individuals engage in such forms of collective action as violent forms of protest or civil disobedience. ${ }^{24}$ Relative deprivation refers to a comparison process whereby one perceives the self (egoistic deprivation) or the ingroup to which one belongs (fraternal deprivation) as not being granted what they deserve. This implies that one is slighted, not treated with the respect that one merits, prompting a sense that others regard one as insignificant. In turn, the latter may evoke feelings of anger and resentment, and motivate behavior aimed at restoring the imbalance.

Yet, SQT and relative deprivation theories differ in a couple major respects. First, relative deprivation refers to the case where one feels unjustly disrespected by others, whereas the loss of significance notion pertains also to cases where one's sense of insignificance was brought upon oneself by dint of one's own regretful and inappropriate (e.g., sinful) actions for which one wishes to expiate. Secondly, according to relative deprivation theory, only deprivation related to one's group membership may potentiate action on behalf of the collective, so that "feeling deprived may inspire participation in collective behavior, but only if the person feels deprived on behalf of a relevant reference group." 25 SQT suggests, instead, that individual-based loss having little to do with group deprivation can induce feelings of insignificance and a search for opportunities for significance restoration. Such search may focus one onto what is important for the ingroup, and the means offered by the group for enhancing one's significance. In cases of intergroup conflict, typically, an important road to significance is the readiness to sacrifice oneself for the group's cause in fighting its enemies. It is in this way that the loss of personal or group-based significance may contribute to extreme group-based action. ${ }^{26}$ In essence then, whereas relative deprivation may induce a sense of significance loss, not all significance loss is based on relative deprivation. Hence, the significance loss concept represents the broader motivational category of which relative deprivation is a special case. 


\section{Threat of loss}

Closely related to actual loss of significance is potential loss that would be experienced should one refuse a suicide mission. Persons who pride themselves on their commitment to a group would suffer humiliation and accusations of hypocrisy/inauthenticity in case they refrained from risking their lives in defense of their group's cause. Japanese Kamikaze pilots of World War II, for instance, had little appetite for dying, nor did they expect rewards in the afterlife. ${ }^{27}$ They volunteered, nonetheless, because rejecting the call to duty would have bestowed upon them and their families vast dishonor, more intolerable, apparently, than an honorable demise.

\section{Opportunity for significance gain}

Often times, the primary motive may not be the undoing of an unusual personal misery or humiliation. Suicide attackers may not be destitute, poorly educated, nor suffering from abuse or discrimination, but instead seemingly well-to-do with excellent future prospects. These individuals may not experience any particular sense of personal humiliation or pain of disrespect from others. Instead, such attackers are often motivated by the allure of becoming a celebrated hero or "larger than life figure." ${ }^{28}$ Rallying to the defense of their group and joining the ranks of suicide attackers affords this opportunity for glorious significance that may prove irresistible. The motive here may not be to simply move away from feelings of insignificance, as may be the case with significance loss, but to move toward superstardom, that is, great significance that normal life circumstances can rarely afford.

It will be noted too, that opportunities for significance gain are not restricted to the grievances of one's own group and may also arise from the apparent injustice to other groups, or even to occurrences unrelated to group phenomena altogether. For instance, large numbers of foreign nationals volunteered for the Spanish Civil War to fight on behalf of the Nationalists or the Republicans even though the issues at stake did not involve their own groups or social identities. ${ }^{29}$ Similarly, Lord Byron and other European intellectuals volunteered to fight along with Greek revolutionaries in the Greek independence war. ${ }^{30}$ In yet other instances, an opportunity for significance gain may entail heroic acts on behalf of individuals in distress, or generally any acts in defense of one's culture's sacred values. ${ }^{31}$ In brief then, although significance loss often offers opportunities for significance gain-it isn't an exclusive source of such opportunities. Accordingly, in the present study we empirically separated attackers' reasons in the significance loss category from those related to significance gain in order to observe whether they systematically differed between different types of suicide bombers.

\section{Interplay of motivation, ideology, and social processes: The three Ns of radicalization}

SQT proposes that the decision to become a suicide attacker represents a conjunction of three factors: a) Need: the motivation to gain (or restore) personal significance as proposed above, b) Narrative of the ideology that touts a suicidal mission as a superior, significance- 
bestowing, means to that end, and c) Networks governed by the social process of group dynamics that persuade the individual to embrace the ideology.

We have already discussed the Need part of that conjunction, namely the quest for significance described earlier. Such motivation defines a goal of significance gain or restoration, whereas the ideological Narrative identifies a means of attaining that goal. Specifically, when one's group is dealt a humiliating blow that insults its sacred values, ${ }^{32}$ an ideology might require its adherents to come to the group's defense and avenge the affront. The ideology also pledges significance and honor to those who put the group first, the greatest honor going to those who are willing to give all and offer their lives for the cause.

Finally, persuasive force (the Network aspect mentioned above) applied by the social process to which one is exposed is also required to get an individual to commit him or herself to the ultimate sacrifice. ${ }^{33}$ Because individuals' beliefs are anchored in the shared reality of groups ${ }^{34}$ to which they belong, they can be persuaded that suicide for a cause is a legitimate and admirable tool of struggle, particularly if they experienced a loss of significance of some sort and saw suicide for the group as an effective way to significance boost. Such persuasion processes can transpire spontaneously and naturally within a group of friends (a "bunch of guys" ${ }^{35}$ ), but they can also be engineered by organizations that identify susceptible candidates and dispatch recruiters to exploit their vulnerability. Indeed, suicide terrorists, relative to non-suicide terrorists and organizers of suicide attacks, had "characteristics [that] converge on a [avoidant and dependent] personality style and ego structure that is susceptible to social influence, especially by persons perceived as authoritative." ${ }^{36}$ Attackers were further described as "longing for interpersonal relationships" and "always in need of reassurance" (i.e., with shaky sense of personal significance), qualities that would make them more susceptible to the influence of both friends within their social network or organizational recruiters. ${ }^{37}$

\section{Manifestations of significance quest as a function of demographics}

With the foregoing notions in mind, we approached a database of suicide attackers and explored the motivational underpinnings of their actions. Our goal was not to identify what motivates one to become a suicide attacker relative to other terrorists. Instead, we aimed to catalogue various motivating circumstances of suicide attackers, using the quest for significance framework as a conceptual tool, to help determine if these motivating circumstances differed systematically for attackers with various demographic characteristics. We also examined if the degree of suicide attackers' quest motivation was related to the potency of their attack. Attackers with the greatest yearning for significance may also feel like they have more riding on their actions, which would increase their motivation and ultimately translate into their greater effectiveness as attackers.

Past research supporting the basic tenets of SQT has largely focused on significance loss. Work with former members of the Liberation Tigers of Tamil Eelam (LTTE), for instance, found that self-reported feelings of insignificance were correlated with support of the violent struggle against the Sinhalese majority. ${ }^{38}$ Likewise, feelings of insignificance have been found to correlate with and increase one's identification as a group member, ${ }^{39}$ which subsequently increased one's willingness to self-sacrifice on the group's behalf. ${ }^{40}$ The present effort, however, examined both significance loss and significance gain. 
Moreover, whereas past research, like that conducted with the LTTE, utilized samples of former radicals and relied on their self-reports, the present study provided a unique opportunity to examine actual suicide attackers via their depictions in open-source materials.

Some critics of SQT argued that if most motivations of extremists can be interpreted as significance seeking, then the concept has little explanatory power or practical application. ${ }^{41}$ In response, we have suggested that the theory's utility lies in its (falsifiable) identification of the general conditions under which significance quest would be aroused, notably when significance is lost or the opportunity for significance gain presents itself, as documented elsewhere. ${ }^{42}$ Particularly in the present analyses, this distinction between loss and gain leads to interesting hypotheses that would be obscured without the assumption of a common underlying motive. We derive these hypotheses from an extensive psychological literature that has established clear differences in approach (gain) and avoidance (loss) motivations across a variety of demographic characteristics. ${ }^{43}$ We therefore expect the same differences to characterize the motivations of suicide attackers, as outlined below.

\section{Gender}

Psychological research on gender differences in approach-avoidance motivations suggests that female suicide attackers may be more likely than males to suffer significance loss, perhaps prompting their decision to embark on a suicide mission. A number of studies have found that women, relative to men, have higher Behavioral Inhibition System (BIS) scale scores (related to loss motivation), and lower scores than men on several subscales of the Behavioral Approach System (related to gain motivation), though not on the overall BAS score. ${ }^{44}$ Moreover, whereas men tend to construe themselves in terms of collectives or groups, women tend to construe themselves in terms of close interpersonal relationships. ${ }^{45}$ This suggests that female suicide attackers should be more likely to experience and respond to varieties of significance loss related to relational concerns, such as violent death of a family member at the hands of the enemy. ${ }^{46}$

\section{Educational level}

Well-educated attackers may be more likely to exhibit a significance gain motivation. Initiating and achieving higher education goals likely requires an appetitive self-regulatory motivation, due to the focus on the ultimate reward of a degree and a fruitful career, as well as the drive required to maintain one's efforts toward that goal, two key components of the BAS. ${ }^{47}$

\section{Age}

Research from several domains of inquiry suggests that older (vs. younger) suicide attackers may be more likely to experience a significance loss (vs. gain) motivation. First, older people place greater emphasis on loss-prevention or maintenance goals, whereas younger people focus more on personal growth or gain goals. ${ }^{48}$ Likewise, research on regulatory focus in the health domain has found that younger individuals are more motivated by promotion concerns, whereas older individuals are equally or more 
motivated by prevention concerns. ${ }^{49}$ Secondly, research has shown that older adults are less likely to engage in a search for meaning or purpose in life (reflecting concern with significance gain), as they are likely already in possession of such a sense. ${ }^{50}$ Accordingly, younger attackers may be more likely to have had personal circumstances that indicate the quest for significance gain (e.g., seeking honor and purpose/meaning in life), whereas older attackers may be more attuned to significance loss experiences.

\section{Family status}

Lastly, attackers' family situation (i.e., marital status and number of children) may relate to the type of significance quest they evinced prior to the attack. Attackers who are married or have children, in essence, have "more to lose" than their single and childless counterparts. This may instill a motivational orientation whereby one is more concerned with losing what one has, and less concerned with what might be gained. Thus, married attackers and those with children may prove especially sensitive to the possibility of significance loss, and to be motivated by the desire to avert it.

\section{The present research}

Identifying suicide attackers' motivations is tricky at best. Successful attackers, those who managed to kill themselves in the process, aren't there to be interviewed. Those who have failed or were caught prior to committing the attack can be interrogated, ${ }^{51}$ but even they may not have veridical insights into what motives may have prompted their actions. ${ }^{52}$ Additionally, samples of survivors are likely to be small and possibly unrepresentative of the population of attackers who succeeded in carrying out their mission.

In the present study, we examined open-source reports of suicide attackers for statements and depictions suggestive of motivation. This information was then coded as an indication of significance loss or significance gain motives, in order to examine how these might manifest themselves differently according to the demographic characteristics outlined above.

\section{Method}

\section{Data collection}

Ariel Merari of Tel Aviv University provided the preliminary database containing 2284 individual suicide attackers (with global scope and attack dates from 1974-2008). We included only a targeted subset of cases $(n=786)$, excluding those in Iraq or Afghanistan, due to limited availability of open-source information about individual suicide attackers in these countries. It is important to note that the original database was created without any knowledge of SQT, thus eliminating any potential selection bias imbued by our theoretical perspective. We first vetted this preliminary data set by a) locating the original data sources, b) double-checking all entered variables, and c) excluding all cases $(n=5$; $0.006 \%$ of the total cases) where questions remained about whether the incident constituted a suicide attack. A team of researchers then conducted a systematic open-source expansion through the use of general Internet searches (e.g., Lexis Nexis, Google, terrorist 
organizational websites) and various terrorism databases. ${ }^{53}$ Information on the motivations and precipitating causes of suicide attacks was extracted without regard to specific content, and later coded according to categories of theoretical interest. Specifically, we searched for information about the attackers' or organizations' motives for committing the attacks, personal information about the attacker and/or the attacker's family/friends, and the intended targets of attack.

\section{Data coding}

The coding scheme was derived from top-down (theory-driven) and bottom-up (data driven) methods. Two researchers independently coded the qualitative information. A third researcher reconciled any differences between them. In the final stage, a fourth researcher reviewed the reconciliation coder's work, and indicated any coding disagreements. As the codes were dichotomous (i.e., either present or absent), inter-rater reliabilities between the reconciliation coder's ratings and the final researcher's ratings were calculated using Cohen's kappa (see Table 1). The coding categories are described below.

\section{Significance loss}

Motivations or circumstances representing significance loss were organized into four meso-level categories representing varieties of loss (see Table 1). Shame represented various circumstances that would bring humiliation to either the individual suicide attacker or his/her family, or information concerning the individual's motivation to alleviate shame. Family death comprised the death of parent(s), sibling(s), or significant

Table 1. Variables used to identify significance quest motivation.

\begin{tabular}{|c|c|c|c|}
\hline \multirow{2}{*}{$\begin{array}{l}\text { Macro-level } \\
\text { Category }\end{array}$} & \multicolumn{2}{|c|}{ Meso-level } & \multirow{2}{*}{$\frac{\text { Micro-level }}{\text { Category }}$} \\
\hline & Category & Frequency & \\
\hline \multirow[t]{4}{*}{$\begin{array}{l}\text { Significance Loss } \\
\quad \text { (Cohen's } \mathrm{K}=.72 \text { ) }\end{array}$} & Shame & 15 & $\begin{array}{l}\text { Attacker allegedly committed adultery } \\
\text { Attacker was allegedly infertile } \\
\text { Attacker allegedly collaborated with "enemy" } \\
\text { Attacker wanted to alleviate shame } \\
\text { Attacker's parents were divorced } \\
\text { Family member was allegedly infertile } \\
\text { Family member allegedly committed adultery } \\
\text { Family member allegedly collaborated with "enemy" } \\
\text { Family member wanted to alleviate family shame } \\
\text { Family member was unemployed } \\
\text { Family member had a personal failure }\end{array}$ \\
\hline & Family death & 23 & $\begin{array}{l}\text { Attacker was a widower } \\
\text { One or both of attacker's parents was deceased } \\
\text { Attacker's sibling(s) were deceased }\end{array}$ \\
\hline & Conflict & 3 & $\begin{array}{l}\text { Attacker had fight or breakup with romantic partner or family } \\
\text { member } \\
\text { Attacker was divorced }\end{array}$ \\
\hline & Failure & 20 & $\begin{array}{l}\text { Attacker was currently unemployed } \\
\text { Attacker had a personal failure }\end{array}$ \\
\hline \multirow[t]{3}{*}{$\begin{array}{l}\text { Significance gain } \\
\quad \text { (Cohen's } \mathrm{K}=.76)\end{array}$} & Reward & 7 & $\begin{array}{l}\text { Attacker paid or financially supported by sponsor prior to attack } \\
\text { Attacker's family financially supported post-mortem }\end{array}$ \\
\hline & Purpose & 7 & $\begin{array}{l}\text { Attacker wanted a sense of purpose or meaning in life } \\
\text { Attacker allegedly lacked life direction/purpose before attack }\end{array}$ \\
\hline & $\begin{array}{l}\text { Religious } \\
\text { Martyrdom }\end{array}$ & 94 & $\begin{array}{l}\text { Attacker wanted to fight in jihad, struggle, holy war } \\
\text { Attacker wanted to be a religious martyr }\end{array}$ \\
\hline
\end{tabular}


other(s). Relationship conflict captured various forms of conflict the attacker experienced with his/her partner or family prior to the attack. Failure represented the attacker's experience of personal failure or unemployment.

\section{Significance gain}

A similar process was implemented to tap significance gain, wherein various gain-relevant circumstances were organized in three meso-level categories (see Table 1). The first category, reward, was used if either the attacker or a family member received monetary payment for the attack. The purpose code was used if the attacker was described as having lacked purpose prior to becoming a suicide terrorist or if he or she expressed wanting to find purpose in his/her life. And finally, the motivation to become a religious martyr or to participate in jihad or holy war was assigned to the category of religious martyrdom. ${ }^{54}$

\section{Demographics}

Demographic information was coded regarding the attacker's gender, age, highest level of education ( 1 = illiterate, $4=$ primary/elementary completed, $7=$ high school completed, 10 = university completed, 12 = advanced degree completed), marital status (single vs. married), and number of children.

\section{Results}

\section{Descriptive statistics}

Open-source information on attackers' motives for committing the attacks and personal information about the attacker and/or the attacker's family/friends were only available for a subset of cases. This enabled us to determine the presence or absence of the aforementioned motivational categories for 219 cases $(27.6 \%$ of the original sample of 781$) .^{55}$ Attacker ethnic group information was available for all 219 cases. Palestinian (37.9\%), Arab-Palestinian (26.5\%), and Arab (17.4\%) constituted the most frequently represented groups. The remaining $18.2 \%$ of cases belonged to nine different ethnic groups (see Table 2). Information on age, education, and number of children was available for 201 (91.7\%), 127 (58.0\%), and 100 (45.7\%) cases, respectively. Results revealed the average suicide attacker to be relatively educated $(M=7.48, \mathrm{SD}=2.07$; i.e., high school graduate), relatively young $(M=23.78, \mathrm{SD}=6.19)$, and without children $(M=0.70, \mathrm{SD}=1.68)$.

Table 2. Frequencies and percentages of attacker's ethnic or cultural group.

\begin{tabular}{lcc}
\hline Ethnicity or culture & Frequency & Percentage \\
\hline African-Arab & 4 & 1.8 \\
African-Jamaican & 1 & 0.5 \\
Afro-Caribbean & 1 & 0.5 \\
Arab & 38 & 17.4 \\
Bengali & 3 & 1.4 \\
Chechen & 13 & 5.9 \\
Javanese & 4 & 1.8 \\
Kashmiri & 3 & 1.4 \\
Kurdish & 5 & 2.3 \\
Palestinian & 83 & 37.9 \\
Tamil & 6 & 2.7 \\
Arab-Palestinian & 58 & 26.5 \\
\hline
\end{tabular}


Information on gender and marital status was available for 219 (100\%) and $160(73.1 \%)$ cases, respectively. The sample was predominantly male (86.8\%) and single (85.0\%). Given the varied availability of information, individual analysis utilized different sample sizes (i.e., analyses of age pertain to 201 participants, whereas analyses of gender pertain to 219 cases).

\section{Presence of the significance quest motive: The research hypotheses}

\section{Personal significance quest codes}

Of the 219 cases, 149 (68.04\%) contained information indicative of a significance loss or gain motive: Ninety-one evinced gain, thirty-seven evinced loss, and twenty-one evinced the presence of both motivations. For the remaining seventy individuals, qualitative information was available and coded by researchers, but it did not pertain to either significance gain or loss. Table 1 shows the frequencies of the meso-level significance quest codes, organized by their superordinate categories. Attackers received a code $(0=$ absent, 1 = present) indicating the presence of one of these superordinate motives, but that motive could have been evidenced by multiple meso-level codes (e.g., an attacker that experienced both shame and family death would have the same significance loss code as an attacker that only experienced shame). Therefore, the frequencies in Table 1 exceed the total number of attackers with available significance quest information.

\section{Significance quest differences by ethnicity}

We first examined cultural differences. Individuals identified as Arab, Palestinian, or Arab-Palestinian were collapsed into a single group. Given insufficient numbers of the remaining ethnic groups (see Table 2), they were likewise collapsed into a single group of "all other attackers," and compared to Arab-Palestinians. Analyses first examined demographic differences between these groups. Age, education, and number of children were subjected to separate one-way ANOVAs with ethnicity as the predictor. The groups only differed on education level (all other $p$ s $>.479$ ), $F(1,126)=5.43, p=.021, \eta^{2}=.04$, with Arab-Palestinians being significantly more educated $(M=7.64, \mathrm{SD}=1.80)$ than other attackers $(M=6.33, \mathrm{SD}=2.31)$. Separate binary logistic regressions with ethnicity $(0=$ Arab-Palestinian, $1=$ other $)$ predicting gender $(0=$ female, $1=$ male $)$ and marital status ( 0 = single, $1=$ married) were also conducted. Arab-Palestinian attackers were nearly seven times more likely to be male $(92.1 \%)$ than other attackers $(63.4 \%): \chi^{2}(1, N=219)=$ 19.33, $p<.001, \beta=-1.91, p<.001, O R=6.76$. Likewise, Arab-Palestinian attackers were $76 \%$ less likely to be married $(12.4 \%)$ than other attackers $(37.5 \%): \chi^{2}(1, N=161)=5.65$, $p=.018, \beta=-1.44, p=.012, O R=.24$. Although both groups (Arab-Palestinian vs. others) were predominantly male and single, these proportions were significantly more pronounced among Arab-Palestinians.

We then examined whether the significance quest manifested differently for ArabPalestinians relative to other attackers. Separate binary logistic regressions were conducted on the presence of significance loss and gain $(0=$ absent, $1=$ present $)$. Arab-Palestinian attackers were $63 \%$ less likely to have suffered significance loss $(22.5 \%)$ than other attackers (43.9\%): $\chi^{2}(1, N=219)=7.28, p=.007, \beta=-.99, p=.006, O R=.37$. Arab-Palestinian attackers, on the other hand, were nearly three times more likely to have anticipated significance gain (55.6\%) relative to other attackers $(31.7 \%): \chi^{2}(1, N=219)=8.21$, $p=.004, \beta=1.05, p=.006, O R=2.85$. Supplemental analyses revealed that this difference 
on significance gain was predominantly driven by the emphasis placed on religious martyrdom within Arab-Palestinian suicide bomber culture. Analyses conducted using a code comprised of all forms of gain except religious martyrdom failed to reveal cultural differences: $\chi^{2}(1, N=219)=1.00, p=.317$.

In the sections that follow, we examined our hypotheses regarding gender, education, age, and family status on significance loss and gain. Given the above-described cultural differences, all subsequent analyses included ethnicity. This enabled us to examine whether the various demographics interacted with ethnicity, or had effects on significance loss and gain above and beyond the already found ethnic group differences.

\section{Significance quest differences by gender}

Based on evidence that women have higher BIS, that is, avoidance oriented (but not BAS) scale scores than men, ${ }^{\mathbf{5 6}}$ we specifically hypothesized greater odds of loss motivation among women. We, therefore, conducted a binary logistic regression with gender $(0=$ female; 1 = male), ethnicity, and their interaction predicting the presence of significance loss. The interaction was not significant $(p=.616)$, so it was removed. The subsequent model predicted significance loss: $\chi^{2}(2, N=219)=15.22, p<.001$. Only the gender effect was significant: $\beta=1.24, p=.005, O R=3.45$. As such, after controlling for ethnicity $(p=.097)$, female attackers were three and half times more likely to have suffered a significance loss than males.

Females were also expected to have a higher likelihood of significance loss reasons for embarking on suicidal missions that were related to relational concerns, namely, family death and relationship conflict. In many instances, it has been noted that an individual's decision to volunteer for a suicide mission was prompted by the loss of a significant person (or persons) in one's life. Consider the case of Hnadi Taisir Jaradat, who killed twenty-one and wounded sixty, during her attack at the Maxim restaurant in Haifa, Israel. Four months prior, Jaradat witnessed the killing of her younger brother and cousin (who also happened to be her lover) at the hands of the Israeli Defense Forces (IDF). Analyses of the Chechnyan Black Widows also attest that the decision to volunteer for suicide missions occurred in the wake of having a spouse or fiancé killed by the enemy. ${ }^{57} \mathrm{We}$ hypothesized that having a close person wrested away from oneself induces a sense of helplessness and powerlessness. Given the importance of relationship concerns to women, relative to their male counterparts, such instances should be more prominent in the motives of female attackers.

In the family death analyses, the interaction term was again non-significant $(p=.406)$ and hence it was removed. The resulting model predicted family death: $\chi^{2}(2, N=219)=$ $29.19, p<.001$. After controlling for ethnicity $(p=.60)$, female attackers were thirteen times more likely to experience a family death than were males: $\beta=2.57, p<.001, O R=13.09$. As for relationship conflict, although the omnibus test was significant, $\chi^{2}(2, N=219)=5.82$, $p=.054$, neither ethnicity $(p=.297)$ nor gender $(p=.131)$ were significant predictors.

Binary logistic regressions were also performed on indicators of significance gain. The interaction was once again removed because it was non-significant $(p=.743)$. The resulting model predicted significance gain: $\chi^{2}(2, N=219)=13.76, p=.001$. In contrast to the significance loss results, after controlling for culture $(p=.060)$, females were $67 \%$ less likely than males to have evinced the significance gain motivation: $\beta=-1.11, p=.019, \mathrm{OR}=.33$. 


\section{Significance quest differences by educational level}

As elaborated earlier, we expected greater significance gain motivation among highly educated attackers. Education level was treated as a continuous variable, as it consisted of twelve monotonically increasing levels, beginning with illiteracy and ending with completion of an advanced degree. There was no Ethnicity $\times$ Education interaction $(p=.161)$, so the term was removed from the model. Although the omnibus test was only marginal, $\chi^{2}(1, N=127)=4.71, p=.095$, there was a significant effect of education, $\beta=.21, p=.042, O R=1.23$, but not of ethnicity $(p=.867)$. As can be seen in Figure 1 , as education level increased, the probability that an attacker experienced a gain motivation increased. Take for instance an individual whose highest level of education was the completion of primary school (i.e., a "4" in Figure 1). If this attacker was Kurdish, he was predicted to have a $38 \%$ chance of experiencing significance gain. If that same individual were Arab, he would have a nearly identical $41 \%$ chance of gain. No differences as a function of education or ethnicity were found for the presence of significance loss: $\chi^{2}$ $(1, N=127)=4.16, p=.245$.

\section{Significance quest differences by age}

Given past research on loss prevention ${ }^{58}$ and the search for meaning or purpose, ${ }^{59}$ we expected that as age increased, loss would predominate over gain motivation. We first examined significance gain. Once again, ethnicity did not interact with our predictor $(p=.144)$, so the interaction term was removed from the model. Although the resulting model was significant, $\chi^{2}(2, N=201)=11.02, p=.004$, this was driven solely by the previously reported cultural difference $(p=.002)$, hence age was not a significant predictor of gain $(p=.998)$.

Analyses conducted on significance loss indicators, however, confirmed our hypotheses: $\chi^{2}(2, N=201)=12.78, p=.002$. In this case, the interaction was not significant $(p=.114)$. There was a significant effect of age, such that after controlling for the significant effect of ethnicity, $\beta=-1.08, p=.006, O R=.34$, the odds of experiencing loss increased with age: $\beta=.07, p=.028, O R=1.07$. Although the probability of loss increased with age for all

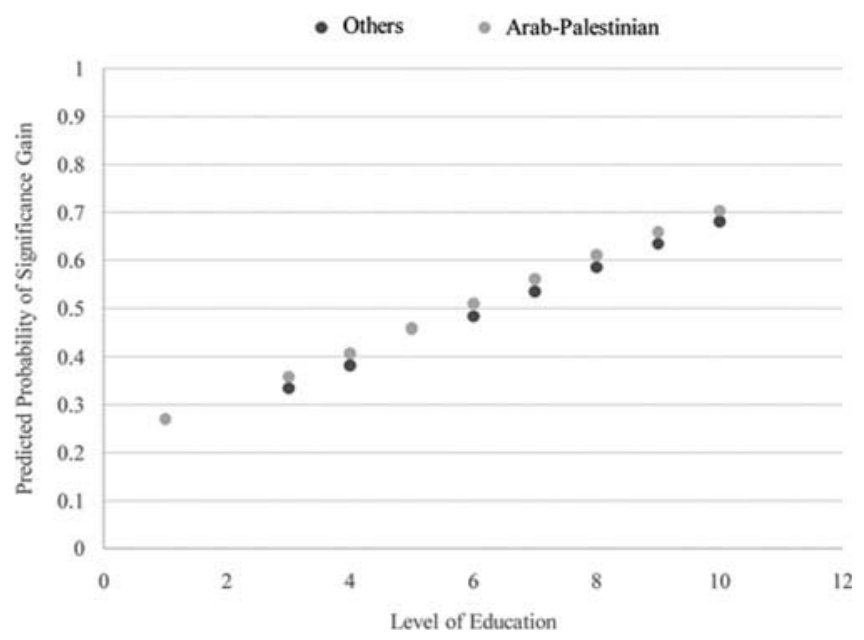

Figure 1. Significance gain as a function of education level and ethnicity. Note. Education was coded such that $1=$ illiterate, $4=$ primary/elementary completed, $7=$ high school completed, $10=$ university completed, 12 = advanced degree completed. 


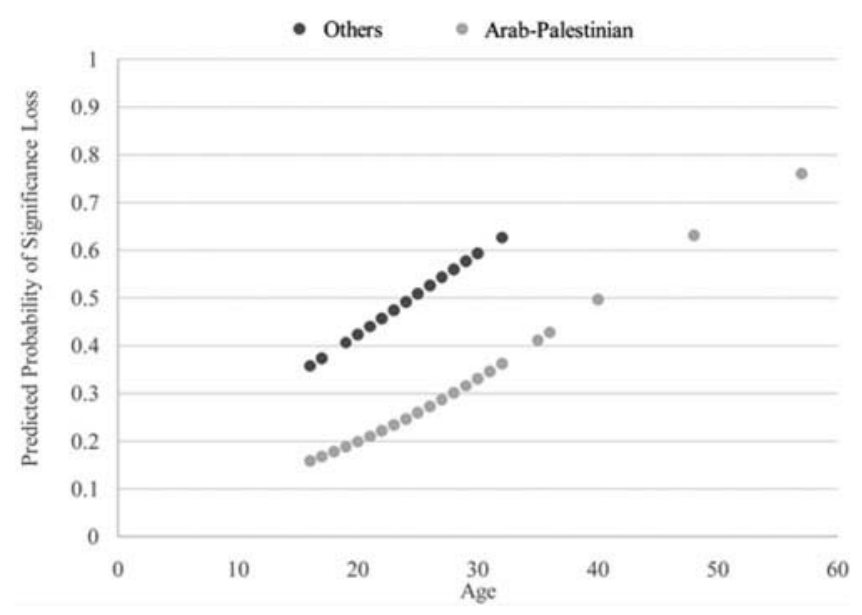

Figure 2. Significance loss as a function of age and ethnicity.

types of attackers, at every age level, Arab-Palestinian attackers were roughly $20 \%$ less likely to have experienced loss. For instance, a 17-year-old Chechen or Tamil attacker was predicted to have a $37 \%$ chance of significance loss, whereas his or her 17-year-old counterpart in Palestine was predicted to have only a $17 \%$ chance of loss (see Figure 2).

\section{Significance quest differences by family status}

Suicide attackers who are married and/or have children should have more to lose, and should therefore be more motivated by significance loss than their single and childless counterparts. There were no effects of marital status on either significance loss or gain ( $p s=.759$ and .472 , respectively). Analyses of the number of children, likewise, failed to predict significance gain $(p=.257)$. There was, however, an Ethnicity $\times$ Children interaction on the presence of significance loss: $\chi^{2}(3, N=100)=15.16, p=.002, \beta=2.13$, $p=.055, O R=8.42$. As depicted in Figure 3, this hypothesis was supported among Arab-

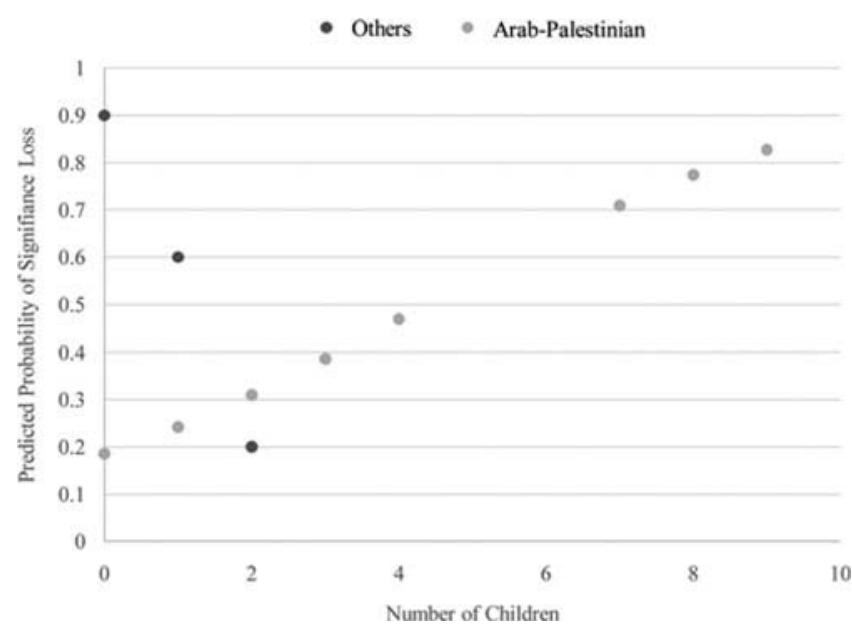

Figure 3. Significance loss as a function of number of children and ethnicity. 
Palestinian attackers - as the number of children increased, the probability of experiencing loss also increased: $\beta=.34, p=.031$. The effect was in the opposite direction yet not significant for all other attackers: $\beta=-1.79, p=.102$. This latter effect should be interpreted with caution as data was missing for $75 \%$ of the non-Arab-Palestinian cases. Moreover, number of children was correlated with age: $r(96)=.78, p<.001$. In a binary logistic regression controlling for age, the Ethnicity $\times$ Children interaction was reduced to non-significance $(p=.999)$, demonstrating that age differences fully accounted for the effect of number of children on the presence of loss.

\section{Significance quest and number of casualties}

Given the proposition that the actions of a suicide attacker are driven by significance quest, those individuals with the greatest yearning for significance may also feel like they have more riding on their actions. This could ultimately translate into the latter individuals being more effective attackers, as measured by the number of casualties per assault. Number of casualties was operationalized with two variables: number killed and number wounded. Both variables were positively skewed (Killed: Skewness $=5.16, \mathrm{SE}=.17$; Wounded: Skewness: $4.56, \mathrm{SE}=.17)$, as most attacks resulted in few casualties. A constant (1) was thus added to each score and a logarithmic $\left(\log _{10}\right)$ transformation was conducted to improve the skew to acceptable levels (Killed: Skewness $=1.50, \mathrm{SE}=.17$; Wounded: Skewness $=.42, \mathrm{SE}=.17$ ).

In the analyses reported thus far, we did not have predictions regarding the degree of quest motivation, but merely the presence of specific forms of quest motivation. For instance, although we predicted (and found) that significance loss was more likely to be present for female (vs. male) attackers, we did not predict females would have more instances of loss than males. Indeed, if females are more motivated by loss, a single incident of family death may be sufficient to push them toward extreme behavior. Nonetheless, it is of interest to consider whether the different sources of significance motivation exert a cumulative effect. We thus created a continuous measure of that motivation by summing over all of its sources at the micro-level. Scores ranged from $0-4$, with 0 representing no indication of significance quest, and four representing an individual with four different indicators of that quest $(M=.94, \mathrm{SD}=.95)$. The same process was repeated specifically summing only instances of significance loss (range $=0-4$; $M=.33, \mathrm{SD}=.67$ ), and only instances of significance gain (range $=0-3 ; M=.61$, $\mathrm{SD}=.75)$.

We first examined if other variables in the dataset related to casualties. Past research suggests that women, educated, and older attackers may be more likely to perpetrate highcasualty attacks. ${ }^{60}$ In the present sample, only education was related to number killed, $r$ $(127)=.22, p=.015$, and wounded, $r(120)=.18, p=.054$ (all other $p$ s $>.10$ ). We thus conducted partial correlations controlling for the effect of education. As predicted, even after controlling for education, degree of significance quest was positively and significantly correlated with both number killed, $r(124)=.47, p<.001$, and wounded, $r(117)=.38$, $p<$ .001 . Similarly, degree of gain correlated with number killed, $r(124)=.52, p<.001$, and wounded, $r(117)=.37, p<.001$, but degree of loss did not (both $p s>.21)$.

Finally, we ruled out the alternative explanation that these significant correlations may be an artifact of high-casualty attacks receiving greater press and journalistic attention, therefore leading to a greater amount of motivational information available in open- 
source reports. ${ }^{61}$ If this were the case, attackers with more available information would also commit higher casualty attacks. Attackers ranged from having five pieces of information to having as many as twenty-one pieces of information $(M=12.37, \mathrm{SD}=2.67)$. Amount of information, however, was not correlated with number killed or wounded (both $p$ s $>.10$ ), and when controlling for this variable, the previously reported correlations remained significant (all $p$ s $<.005$ ).

\section{Discussion}

Analyses carried out on a database of suicide attackers yielded results regarding a) the relationship between the significance quest motivation and potency of the suicide attack, and b) systematic differences in the manifestation of the significance quest motive according to various demographics. More specifically, the analyses looking at attack potency revealed that this relationship between significance quest motivation and casualties was driven by significance gain, not loss. There are several possible explanations for this correlation. First, the stronger the significance gain motivation, implied by the number of relevant indicators, the greater might be individuals' effort toward ensuring success in their attack. Secondly, an intense yearning for high levels of significance could be related to an increased willingness to volunteer for high-value targets that involve high casualties. These high-value targets are likely more crucial to success of the insurgent group and more likely to receive ample media attention. Consequently, these attacks pose a greater potential for significance gain. Thirdly, and relatedly, the organizational launchers of suicide attacks could specifically recruit individuals with a stronger significance yearning for high-value targets because of the assumption that they will be more insistent and ultimately more successful. In this vein, past research has found that older and more educated attackers are more likely to be involved in both highly important missions, and missions that resulted in high numbers of casualties. ${ }^{62}$ The present research suggests that, along with maturity and intellect, an intense yearning for significance may render attackers particularly valuable to terrorist outfits.

An interesting question for future research, however, is why these correlations were not likewise found between the degree of significance loss and number of casualties. It could be that gain and loss motivations operate differently. One could imagine that circumstances that increase the quest for significance gain have an additive effect on behaviorthe more enveloped one is in the search for supreme meaning or significance, the more committed one becomes and the more attracted one is to high-value targets, as discussed above. Attackers with increasing experiences of loss, on the other hand, may often become dejected, stuck in a state of learned helplessness, or be unsure of their own abilities. They may perceive suicide bombing as a remedy to this state, but be unwilling to volunteer for high-value attacks because of their lesser likelihood of success. It is also possible that redeeming a loss, like prevention focus, ${ }^{63}$ requires merely a return to a base line of significance, whereas effecting a gain, like promotion focus, requires exceeding the baseline of significance and attaining greater impact, which possibly requires greater effort that translates into impact as measured by casualties.

Additionally, and of particular interest, we found that the manifestation of the significance quest motivation varied systematically in accordance with attackers' ethnicity, gender, age, and education. The majority of the present sample was Arab-Palestinian in origin. 
Although the agreed-upon characterization of suicide attackers is male, young, single, and relatively educated, ${ }^{\mathbf{6 4}}$ this characterization was more pronounced among Arab-Palestinian attackers in our sample. It has been suggested that the greater proportion of males in these regions is due to the emphasis on Islamic fundamentalism, but future research may wish to examine this directly. ${ }^{65}$ Arab-Palestinian attackers were also less likely to have experienced significance loss, and more likely to have anticipated significance gain, an effect apparently driven by the emphasis placed on martyrdom among Arab attackers.

Female attackers, relative to males, had greater odds of significance loss, and lower odds of significance gain. The latter finding was unexpected given the absence of gender differences in gain motivation found in previous research using the approach-related BAS scale. ${ }^{66}$ Approach motivation may manifest differently in cultures represented in our sample than in cultures where gender differences in approach motivation have been previously investigated. ${ }^{67}$ Women in our sample (e.g., Palestinian, Kurdish, Islamic) might be discouraged from significance gain goals (e.g., seeking honor or a sense of meaning in life), and encouraged to pursue less "ambitious" goals commensurate with culturally prescribed gender roles. This suggestion is consistent with observations made about the Chechen Black Widow suicide attackers who, after the experience of trauma, took on more "emancipated" roles that were previously reserved for men. ${ }^{68}$

We especially found that female attackers had greater odds of a death in the family precipitating their attack. We did not find, however, that female attackers had greater odds of having an interpersonal conflict prior to the attack. Note that a relationship conflict does not necessarily represent the breakdown of social ties per se. Indeed, single episodes of conflict have no lingering negative impact on individuals' satisfaction with relationships, ${ }^{69}$ and relationship bonds only tend to disintegrate in the face of protracted and recurring conflict. ${ }^{70}$ It is possible that the latter conflicts were rare or completely absent in our sample.

Analyses also revealed that more educated attackers had greater odds of the significance gain motivation. Getting an education is a forward-looking process wherein gains in knowledge are sought out. Immersion in educational activity may thus attest to a gain orientation. Age, on the other hand, was predictive of significance loss but not gain motivation. Thus, and consistent with past research, ${ }^{71}$ younger and older attackers did not differ in the extent to which a gain code was present, but older attackers were more likely to have evinced an instance of significance loss. It appears that age-bred realism and the investment in relations and possessions (i.e., having things to lose) may well contribute to a loss orientation. Indeed, within our sample, older attackers were more likely to have family situations indicative of having more to lose, married attackers were significantly older $(M=27.87, \mathrm{SD}=6.57)$ than single attackers $(M=21.72, \mathrm{SD}=3.11)$, $F(1,157)=51.86, p<.001 ; \eta^{2}=.25$, and number of children increased with age: $r(96)=$ $.78, p<.001$. Interestingly, though, marital status was unrelated to significance loss, and the relationship between number of children and significance loss was entirely explained by age. This suggests that although these important changes in one's life likely contribute to a shift toward an avoidance or prevention orientation, at least in the present sample, it was the third variable of age that accounted for both the family circumstances (number of children) and the found motivational differences in loss versus gain emphasis. 


\section{Limitations of the present study}

Though the present research offers a rare quantitative glimpse at suicide attackers, several limitations warrant explicit acknowledgement. First, our method of analysis on its own is not a sufficient test of significance quest theory. Rather, the SQT framework guided our exploration of the data and proved helpful in obtaining novel findings related to demographics as well as the motivational antecedents of destructive impact (number of casualties) of suicide attackers. Further empirical tools, such as experimental manipulations or qualitative discussions, however, are needed to provide a rigorous test of the mechanisms at work in significance quest processes. Much could be learned from research taking a multi-pronged approach, and we hope the present findings may serve to inspire and complement such efforts. Furthermore, the analyses are based on available open-source information that differed in its degree of completeness for different attackers, and might have been systematically biased. Open-source information likely over-emphasizes personal details about attackers, as this might be the only type of information journalists can ascertain, short of infiltrating terrorist groups. The depiction of female suicide attackers in terms of significance gain might also be deemed inappropriate by informational sources (i.e., the attackers' family, friends, neighbors, media, or the attacker herself) because of prominent cultural or genders mores, and consequently might have been deliberately eschewed in reports on which our analyses were based. Similarly, media may have overrelied on portrayals of suicide attackers as martyrs for a cause. This could have artificially inflated the presence of religious martyrdom, which was the most common instance of significance gain in our database.

Secondly, the present research omitted cases from Afghanistan and Iraq because of limited availability of open-source information. Reports suggest that Afghani attackers may differ importantly from those in other regions-i.e., that they may be less effective, older, less educated, showing high incidence of physical disabilities, and lesser emphasis on martyrdom. ${ }^{72}$ Suicide attackers in Iraq, on the other hand, may differ from the present sample in their emphasis on martyrdom and in their transnational nature, often hailing from neighboring Arab states or Europe. ${ }^{73}$ These differences might translate into different results than those reported herein, and a complete understanding of the motivational underpinnings of suicidal terrorism would necessitate examining these attackers as well. However, the fact that most of the demographic differences in our current sample held after controlling for cultural differences suggests that the findings might also hold with the inclusion of Afghani or Iraqi attacks.

Thirdly, the sample did not include a comparison condition of non-suicidal terrorists. Thus we did not aim to distinguish motivations of suicide attackers from other extremists, but to understand how a specific broad motivational category of special interest (i.e., significance quest) manifests for various types of suicide attackers. Indeed, SQT suggests that the pursuit of significance via intergroup violence may be a general phenomenon not necessarily reserved for suicidal activities. ${ }^{74}$ The quest for significance may also characterize non-suicide extremists, given that their actions likely reflect commitment to their cause and a relative reduction in pursuit of other personal objectives and life aspirations. It is thus possible that motivational differences between suicide and non-suicide attackers would vary in the degree to which the individual focused exclusively on achieving significance through martyrdom, versus considering alternative routes to significance, and alternative objectives. 


\section{A conjunctive look at the demographic findings}

The demographic differences in motivational foci outlined in the present analysis are interesting in and of themselves, but they examine each demographic characteristic in isolation. Suicide attackers are not characterized exclusively by a single demographic (say, their gender), but at the same time by the remaining demographics (i.e., their ethnicity, age, education, and family status). Looking at these qualities conjunctively is quite telling. In our database, the "typical" suicide bomber was a single, somewhat educated, ArabPalestinian male in his early 20s. This confluence of traits creates a "perfect storm" of significance gain motivation. As reported previously, a) men were more likely to have a significance gain circumstance, and less likely to have a significance loss orientation. Similarly, b) educated and c) Arab-Palestinian attackers were more likely to have significance gain. Although we cannot make any conclusive claims on this basis, the present findings suggest that the typical Palestinian suicide bomber, relative to his or her less typical counterpart, may see suicide attacks less as a means of redeeming humiliation or eradicating lost significance, and more as an avenue to potential glory, fame, or hero/ martyr status. Consider Saheib Abdulrahim Timr, an attacker responsible for driving a car bomb into an Israeli school bus, killing eight and wounding more than forty others. Saheib was a "typical" bomber-male, single, 18 years old, and attending university during the time of his attack. There is no indication that he experienced any type of significance loss, at least not personally. The only indication of motive was his yearning for martyrdom status. Indeed, he came from a family of Hamas activists, and it was reported that his path to jihad began very early in life.

Correspondingly, our evidence suggests that the power of loss may motivate women and older individuals-those with "atypical" qualities-to join the ranks of suicide attackers. Fatima Omar Muhammed Al-Najar is a clear example as a 57-year-old woman without evidence of a formal education. Fatima detonated an explosive device while approaching IDF forces in the Gaza Strip, Israel. Fatima witnessed the killing of sixty civilians during the shelling of Beit Hanon, she lived in a one-room shack because her home had been demolished, she lost her husband a year prior, a son and grandson were killed by Israelis, another grandson was crippled, and finally, five of her seven sons had spent time in Israeli jails. This overwhelming slew of losses may very well have been her impetus for becoming a suicide attacker.

\section{Conclusion}

The present findings afforded insights into systematic variations of the significance quest motive as a function of demographic characteristics. Should the results be replicated, and the limitations addressed, they would carry potentially important implications for counter-radicalization policy and guide differential counter-radicalization strategies for segments of vulnerable populations. For instance, counter-radicalization strategies aimed at the motivational foci of highly effective groups-the educated, female, and older attackers that often commit high-value, high-casualty attacks ${ }^{75}$-may prove fruitful in reducing the use of suicide attacks as the strategy of choice among terrorist organizations. 


\section{Notes}

1. Emile Durkheim, Suicide: A Study in Sociology (New York: The Free Press, 1897); Thomas E. Joiner, Jr., Jessica S. Brown, and LaRicka R. Wingate, "The Psychology and Neurobiology of Suicidal Behavior," Annual Review of Psychology 56 (2005): 287-314; Kimberly A. Van Orden, Tracy K. Witte, Kelly C. Cukrowicz, Scott Braithwaite, Edward A. Selby, and Thomas E. Joiner, Jr., “The Interpersonal Theory of Suicide," Psychological Review 17 (2010): 575-600.

2. Ernest Becker, The Denial of Death (New York: The Free Press, 1973); Jeff Greenberg, Tom Pyszczynski, and Sheldon Solomon, "The Causes and Consequences of a Need for Self-esteem: A Terror Management Theory," in Public Self and Private Self, edited by Roy F. Baumeister (New York: Springer-Verlag, 1986), 189-212.

3. Diego Gambetta, Making Sense of Suicide Missions (New York: Oxford University Press, 2005); Ariel Merari, Driven to Death: Psychological and Social Aspects of Suicide Terrorism (New York: Oxford University Press, 2010); Robert A. Pape, Dying to Win: The Strategic Logic of Suicide Terrorism (New York: Random House, 2005).

4. Bruce Hoffman, "The Logic of Suicide Terrorism," The Atlantic Monthly, June 2003, http:// www.theatlantic.com/magazine/archive/2003/06/the-logic-of-suicide-terrorism/302739/.

5. Riaz Hassan, Suicide Bombings (New York: Routledge, 2011).

6. Pape (see note 3 above).

7. Mohammed M. Hafez, Suicide Bombers in Iraq: The Strategy and Ideology of Martyrdom (Washington, DC: United States Institute of Peace Press, 2007); see also Katherine R. Seifert and Clark McCauley, "Suicide Bombers in Iraq, 2003-10: Disaggregating Targets Can Reveal Insurgent Motives and Priorities," Terrorism and Political Violence 26, no. 5 (2014): 803-820.

8. Bruce Hoffman and Gordon H. McCormick, "Terrorism, Signaling, and Suicide Attack," Studies in Conflict and Terrorism 27 (2004): 243-81.

9. Mia Bloom, Dying to Kill: The Allure of Suicide Terrorism (New York: Columbia University Press, 2005).

10. Joiner et al. (see note 1 above).

11. Scott Atran, "Genesis of Suicide Terrorism," Science 299 (2003): 1534-39; Robert J. Brym, "Six Lessons of Suicide Bombers," Contexts 6 (2007): 40-45; Riaz Hassan, Life as a Weapon: The Global Rise of Suicide Bombings (New York: Routledge, 2010); Pape (see note 3 above); Jerrold M. Post, Farhana Ali, Schuyler W. Henderson, Stephen Shanfield, Jeff Victoroff, and Steven Weine, "The Psychology of Suicide Terrorism," Psychiatry 72 (2009): 13-31; Ellen Townsend, "Suicide Terrorists: Are They Suicidal?," Suicide and Life-threatening Behavior 37 (2007): 35-49; but see Adam Lankford, The Myth of Martyrdom: What Really Drives Suicide Bombers, Rampage Shooters, and Other Self-Destructive Killers (New York: Palgrave Macmillan, 2013).

12. Pape (see note 3 above).

13. Durkheim (see note 1 above).

14. Mohammed M. Hafez, "Rationality, Culture, and Structure in the Making of Suicide Bombers: A Preliminary Theoretical Synthesis and Illustrative Case Study," Studies in Conflict and Terrorism 29 (2006): 165-85.

15. Arie W. Kruglanski, Michele Gelfand, Jocelyn J. Bélanger, Anna Sheveland, Malkanthi Hettiarachchi, and Rohan Gunaratna, "The Psychology of Radicalization and Deradicalization: How Significance Quest Impacts Violent Extremism," Political Psychology 35 (2014): 69-93.

16. Kruglanski et al., "The Psychology of Radicalization and Deradicalization" (see note 15 above); Arie W. Kruglanksi, Jocelyn J. Bélanger, Michele Gelfand, Rohan Gunaratna, Malkanthi Hettiarachchi, Fernando Reinares, Edward Orehek, Jo Sasota, and Keren Sharvit, "Terrorism -A Self Love Story: Redirecting the Significance Quest Can End Violence," American Psychologist 68 (2013): 559-75; Arie W. Kruglanski, Xiaoyan Chen, Mark Dechesne, Shira 
Fishman, and Edward Orehek, "Fully Committed: Suicide Bombers' Motivation and the Quest for Personal Significance," Political Psychology 30 (2009): 331-57.

17. Bloom (see note 9 above); Gambetta (see note 3 above); Jessica Stern, Terror in the Name of God: Why Religious Militants Kill (New York: HarperCollins, 2003).

18. Luca Ricolfi, "Palestinians, 1981-2003," in Making Sense of Suicide Missions, edited by Diego Gambetta (New York: Oxford University Press, 2005), 106.

19. Gregory Elliott, Suzanne Kao, and Ann-Marie Grant, "Mattering: Empirical Validation of a Social-Psychological Concept," Self and Identity 3 (2004): 339-54; Jeremy Ginges, Scott Atran, Douglas Medin, and Khalil Shikaki, "Sacred Bounds on Rational Resolution of Violent Political Conflict," Proceedings of the National Academy of Sciences of the United States of America 104 (2007): 7357-60.

20. Vellupilai Prabakharan, the charismatic leader of the Liberation Tigers of Tamil Eelam, was in the habit of having last supper with a suicide attacker on the eve of the mission.

21. Arie W. Kruglanski, Marina Chernikova, Emily Rosenzweig, and Catalina Kopetz, "On Motivational Readiness," Psychological Review 121 (2014): 367-88.

22. See Elliott et al. (see note 19 above); Ginges et al. (see note 19 above).

23. Ami Pedahzur, Suicide Terrorism (Malden, MA: Polity Press, 2005).

24. James A. Davis, "A Formal Interpretation of the Theory of Relative Deprivation," Sociometry 22 (1959): 280-96; Ted R. Gurr, Why Men Rebel (Princeton: Princeton University Press, 1970); Walter G. Runciman, Relative Deprivation and Social Justice: A Study of Attitudes to Social Inequality in Twentieth Century Britain (Berkeley, CA: University of California Press, 1966).

25. Heather J. Smith, Thomas F. Pettigrew, Gina M. Pippin, and Silvana Bialosiewics, "Relative Deprivation: A Theoretical and Meta-analytic Review," Personality and Social Psychology Review 16 (2012): 203-32.

26. Arie W. Kruglanski, Michele J. Gelfand, and Rohan Gunaratna, "Terrorism as Means to an End: How Political Violence Bestows Significance," in Meaning, Mortality, and Choice: The Social Psychology of Existential Concerns, edited by Phillip R. Shaver and Mario Mikulincer (Washington, DC: American Psychological Association, 2012), 203-12; Arie W. Kruglanski and Edward Orehek, "The Role of Quest for Significance in Motivating Terrorism," in Social Conflict and Aggression, edited by Joseph Forgas, Arie Kruglanski, and Kipling Williams (New York: Psychology Press, 2011), 153-64; Edward Orehek, Jo A. Sasota, Arie W. Kruglanski, Mark Dechesne, and Leianna Ridgeway, "Interdependent Self-construals Mitigate the Fear of Death and Augment the Willingness to Become a Martyr," Journal of Personality and Social Psychology 107 (2014): 265-75.

27. Emiko Ohnuki-Tierney, Kamikaze Diaries: Reflections of Japanese Student Soldiers (Chicago: University of Chicago Press, 2006).

28. Ehud Sprinzak, "The Lone Gunmen: The Global War on Terrorism Faces a New Brand of Enemy," Foreign Policy 1127 (2001): 72-3.

29. Christopher Othen, Franco's International Brigades: Adventurers, Fascists, and Christian Crusaders in the Spanish Civil War (New York: Columbia University Press, 2013).

30. Fiona MacCarthy, Byron: Life and Legend (New York: Farrar, Straus, and Giroux, 2002).

31. Ginges et al. (see note 19 above).

32. Ibid.

33. Marc Sageman, Understanding Terror Networks (Philadelphia: University of Pennsylvania Press, 2004); Marc Sageman, Leaderless Jihad: Terror Networks in the Twenty-first Century (Philadelphia: University of Pennsylvania Press, 2008).

34. Daniel Bar-Tal, Shared Beliefs in a Society: Social Psychological Analysis (Thousand Oaks, CA: Sage Publications, 2000); Curtis D. Hardin and E. Tory Higgins, "Shared Reality: How Social Verification Makes the Subjective Objective," in Handbook of Motivation and Cognition, Volume 3: The Interpersonal Context, edited by Richard M. Sorrentine and E. Tory Higgins (New York: Guilford Press, 1996), 28-84, Kurt Lewin, "Frontiers in Group Dynamics: Concept, Method, and Reality in Social Science; Social Equilibria and Social Change," Human Relations 1 (1947): 5-41.

35. Sageman, Understanding Terror Networks (see note 33 above). 
36. Ariel Merari, Ilan Diamant, Arie Bibi, Yoav Broshi, and Giora Zakin, "Personality Characteristics of 'Self-martyrs'/'Suicide Bombers' and Organizers of Suicide Attacks," Terrorism and Political Violence 22 (2009): 87-101.

37. Merari et al. (see note 36 above).

38. Kruglanski et al., "The Psychology of Radicalization and Deradicalization" (see note 15 above).

39. Kruglanski et al., "Terrorism as Means to an End" (see note 26 above); Kruglanski and Orehek, "The Role of Quest for Significance in Motivating Terrorism" (see note 26 above).

40. Orehek et al. (see note 26 above).

41. Mia Bloom, "Chasing Butterflies and Rainbows: A Critique of Kruglanski et al.'s 'Fully Committed: Suicide Bombers' Motivation and the Quest for Personal Significance,"” Political Psychology 30 (2009): 387-95.

42. See Kruglanski et al., "The Psychology of Radicalization and Deradicalization" (see note 15 above); Kruglanksi et al., "Terrorism-A Self Love Story" (see note 16 above); Kruglanski et al., "Fully Committed" (see note 16 above).

43. Charles S. Carver and Teri L. White, "Behavioral Inhibition, Behavioral Activation, and Affective Responses to Impending Reward and Punishment: The BIS/BAS Scales," Journal of Personality and Social Psychology 67 (1994): 319-33; E. Tory Higgins, "Beyond Pleasure and Pain," American Psychologist 52 (1997): 1280-300.

44. Carver and White (see note 43 above); Stephen Erdle and J. Philippe Rushton, "The General Factor of Personality BIS-BAS, Expectancies of Reward and Punishment, Self-esteem, and Positive and Negative Affect," Personality and Individual Differences 48 (2010): 762-66; Anthony F. Jorm, Helen Christensen, Alexander S. Henderson, Patricia A. Jacomb, A. E. Korten, and B. Rodgers, "Using the BIS/BAS Scales to Measure Behavioral Inhibition and Behavioral Activation: Factor Structure, Validity, and Norms in a Large Community Sample," Personality and Individual Differences 26 (1999): 49-58; Luigi Leone, Marco Perugini, Richard P. Bagozzi, Antonio Pierro, and Lucia Mannetti, "Construct Validity and Generalizability of the Carver-White Behavioral Inhibition System/Behavioral Activation System Scales," European Journal of Personality 15 (2001): 373-90.

45. Roy F. Baumeister and Kristin L. Sommer, "What Do Men Want? Gender Differences and Two Spheres of Belongingness: Comment on Cross and Madson (1997)," Psychological Bulletin 122 (1997): 38-44; Marilynn B. Brewer and Wendi Gardner, "Who Is This 'We'? Levels of Collective Identity and Self-representations," Journal of Personality and Social Psychology 71 (1996): 83-93; Susan E. Cross and Laura Madson, "Models of the Self: SelfConstruals and Gender," Psychological Bulletin 122 (1997): 5-37; Shira Gabriel and Wendi L. Gardner, "Are There 'His' and 'Her' Types of Interdependence? The Implications of Gender Differences in Collective and Relational Interdependence for Affect, Behavior, and Cognition," Journal of Personality and Social Psychology 77 (1999): 642-55.

46. Anne Spekhard and Khapta Akhmedova, "Talking to Terrorists," Journal of Psychohistory 33 (2005): 125-56.

47. Carver and White (see note 43 above).

48. Natalie C. Ebner, Alexandra M. Freund, and Paul B. Baltes, "Developmental Changes in Personal Goal Orientation from Young to Late Adulthood: From Striving for Gains to Maintenance and Prevention of Losses," Psychology and Aging 21 (2006): 664-78; Jutta Heckhausen, "Developmental Regulation across Adulthood: Primary and Secondary Control of Age-Related Challenges," Developmental Psychology 33 (1997): 176-87; Daniel M. Ogilvie, Kristin M. Rose, and Jessica B. Heppen, "A Comparison of Personal Project Motives in Three Age Groups," Journal of Basic and Applied Psychology 23 (2001): 207-15.

49. Penelope Lockwood, Alison L. Chasteen, and Carol Wong, "Age and Regulatory Focus Determine Preferences for Health-Related Role Models," Psychology and Aging 20 (2005): 376-89.

50. Freya Dittmann-Kohli and Gerben J. Westerhof, "The Personal Meaning System in a LifeSpan Perspective," in Exploring Existential Meaning: Optimizing Human Development Across 
the Life Span, edited by Gary T. Reker and Kerry Chamberlain (Thousand Oaks, CA: Sage Publications, 2000), 107-22; S. Read, Gerben J. Westerhof, and Freya Dittmann-Kohli, "Challenges to Meaning in Life: A Comparison in Four Different Age Groups in Germany," International Journal of Aging and Human Development 61 (2005): 85-104; Gary T. Reker and Paul T. P. Wong, "Towards a Theory of Personal Meaning," in Emergent Theories of Aging, edited by James E. Birren and Wern L. Bengston (New York: Springer, 1988), 214-46; Michael F. Steger, Shigehiro Oishi, and Todd B. Kashdan, "Meaning in Life Across the Life Span: Levels and Correlates of Meaning in Life from Emerging Adulthood to Older Adulthood," Journal of Positive Psychology 4 (2009): 43-52.

51. Merari, Driven to Death (see note 3 above).

52. Richard E. Nisbett and Timothy D. Wilson, "Telling More Than We Can Know: Verbal Reports on Mental Processes," Psychological Review 84 (1977): 231-59.

53. Suicide Attack Database [Data file], Chicago Project on Security and Terrorism, 2011, http:// cpost.uchicago.edu/search.php; Worldwide incidents tracking system [Data file], National Counterterrorism Center, 2011, https://wits.nctc.gov; Ami Pedahzur and National Security Studies Center, Terrorism, Insurgencies, and Guerillas in Education and Research (TIGER) Suicide Attacks Worldwide Data [Data file], http://www.laits.utexas.edu/tiger/terrorism_data/ suicide_attacks_worldwide/.

54. For $2 / 3$ of the cases, religious martyrdom was coded from something said by the attacker (i.e., last will/testament, video recording, letter, interview with authorities/media), interviews with friends/family members, or online biographies. For the remaining third, it was coded from a claim made by a sponsoring organization. Analyses revealed that attackers did not differ based on the source of the information, and the pattern of results remained the same when excluding individuals whose martyrdom status was only determined via organizational claim.

55. Information was available for 289 cases. All of the reported analyses, however, included ethnic group as a covariate. Of the 289 cases, ethnicity information was only available for 219 cases. To avoid confusion, we only report descriptives on this reduced set.

56. See Carver and White (see note 43 above); Erdle and Rushton (see note 44 above); Jorm et al. (see note 44 above); Leone et al. (see note 44 above).

57. Spekhard and Akhmedova (see note 46 above).

58. See Ebner et al. (see note 48 above); Heckhausen (see note 48 above); Ogilvie et al. (see note 48 above).

59. See Dittmann-Kohli and Westerhof (see note 50 above); Read et al. (see note 50 above); Reker and Wong (see note 50 above); Steger et al. (see note 50 above).

60. Efraim Benmelech and Claude Berrebi, "Human Capital and the Productivity of Suicide Bombers," Journal of Economic Perspectives 21 (2007): 223-38, Mia Bloom, Bombshell: The Many Faces of Women Terrorists (Philadelphia, PA: University of Pennsylvania Press, 2011); Lindsey A. O’Rourke, “What's Special about Female Suicide Terrorism?” Security Studies 18 (2009): 681-718.

61. We thank a reviewer for this suggestion.

62. Benmelech and Berrebi (see note 60 above).

63. E. Tory Higgins, Beyond Pleasure and Pain: How Motivation Works (New York: Oxford University Press, 2011).

64. Atran (see note 11 above); Gambetta (see note 3 above); Pape (see note 3 above).

65. Pape (see note 3 above).

66. See Carver and White (see note 43 above); Erdle and Rushton (see note 44 above); Jorm et al. (see note 44 above); Leone et al. (see note 44 above).

67. See Carver and White (see note 43 above); Erdle and Rushton (see note 44 above); Jorm et al. (see note 44 above); Leone et al. (see note 44 above).

68. Spekhard and Akhmedova (see note 46 above).

69. Brett Laursen, "The Perceived Impact of Conflict on Adolescent Relationships," Merril-Palmer Quarterly 39 (1993): 535-50.

70. Thomas J. Berndt and Keunho Keefe, "Friends' Influence on Adolescents' Perceptions of Themselves at School," in Student Perceptions in the Classroom, edited by Dale H. Schunk 
and Judith H. Meece (Mahwah, NJ: Lawrence Erlbaum, 1992), 51-73; G. R. Patterson and L. Bank, "Some Amplifying Mechanisms for Pathologic Process in Families," in Minnesota Symposia on Child Psychology, edited by Megan R. Gunnar and Esther Thelan, Vol. 22 (Hillsdale, NJ: Erlbaum, 1989), 167-209.

71. See Ebner et al. (see note 48 above); Heckhausen (see note 48 above); Ogilvie et al. (see note 48 above).

72. United Nations Assistance Mission to Afghanistan, Suicide Attacks in Afghanistan (2001-07), September 2007; Soraya Sarhaddi Nelson, "Diasabled Often Carry Out Afghan Suicide Missions," NPR, October 15, 2007, http://www.npr.org/templates/story/story.php?storyId= 15276485.

73. Hafez, Suicide Bombers in Iraq (see note 7 above).

74. See Kruglanski et al., "The Psychology of Radicalization and Deradicalization" (see note 15 above); Kruglanksi et al., "Terrorism-A Self Love Story" (see note 16 above); Kruglanski et al., "Fully Committed" (see note 16 above).

75. See Benmelech and Berrebi (see note 60 above); Bloom (see note 60 above); O'Rourke (see note 60 above).

\section{Notes on contributors}

David Webber is affiliated with the Department of Psychology, University of Maryland. Kristen Klein is affiliated with the Homeland Security Studies and Analysis Institute (HSSAI), Analytic Services, Inc. Arie Kruglanski is affiliated with the Department of Psychology, University of Maryland. Ambra Brizi is affiliated with the Department of Social and Developmental Psychology, Sapienza University of Rome. Ariel Merari is affiliated with the Department of Psychology, Tel Aviv University. 